V. 13, n. 1: 2017.

\title{
GESTÃO ESCOLAR: MOTIVAÇÃO, ATITUDES E POSSIBILIDADES PARA MELHORAR RESULTADOS
}

\author{
Betina Waihrich Teixeira. Especialista em Gestão Escolar do IF Farroupilha, Campus Júlio de \\ Castilhos; Mestranda em Educação Profissional e Tecnológica do Colégio Técnico Industrial de \\ Santa Maria/Universidade Federal de Santa Maria (UFSM/RS) e Instituto Federal Farroupilha \\ (IFFar/RS) - betinawteixeira@ hotmail.com \\ Silvia de Siqueira. Graduanda do Curso de Licenciatura em Ciências Biológicas do Instituto \\ Federal de Educação, Ciência e Tecnologia Farroupilha Campus Júlio de Castilhos - \\ silviadsiqueira@gmail.com
}

\begin{abstract}
RESUMO: O gestor escolar deve ter uma boa liderança de comunicação, sabendo interagir com sua equipe de trabalho de modo equilibrado e positivo, valorizando o potencial de cada professor. A escola é uma organização que sempre precisou mostrar resultados em relação ao aprendizado dos alunos, porém nem sempre são positivos. Para evitar desperdícios de esforços e fazer com que os objetivos sejam atingidos ano após ano, sabe-se que é necessário a presença da equipe gestora e professores que atuem como líderes, motivadores, capazes de programar ações direcionadas para esse foco. Diante disso, o objetivo deste estudo é investigar quais as formas encontradas pelos gestores e sua equipe para promover a motivação dos professores em sala de aula. Para isso, foram realizadas entrevistas com professores e gestores de escolas do município de Júlio de Castilhos/RS. Considerase relevante este estudo, pois ser professor é uma das profissões que mais teve aumento de tarefas nós últimos tempos e a motivação está ligada diretamente com essa profissão. Percebe-se que os resultados são pertinentes, pois nos remete ao entendimento da importância da motivação no ambiente escolar, assim reflete no bom desempenho de alunos e professores. Diante disso, fica evidente a grande importância que a motivação tem no processo de ensino e aprendizagem e, principalmente, a motivação da equipe gestora que pode influenciar de forma positiva nesse processo.
\end{abstract}

Palavras-chave: Motivação. Gestão. Professores.

\section{SCHOOL MANAGEMENT: MOTIVATION, ATTITUDES AND POSSIBILITIES TO IMPROVE RESULTS}

\begin{abstract}
The school manager must have a good communication leadership, knowing how to interact with his her team in a balanced and positive way, valuing the potential of each teacher. The school is an organization that has always had to show results in relation to the students' learning, but they are not always positive. In order to avoid wasted effort and to achieve the objectives year after year, it is necessary to have the presence of the management team and teachers who act as leaders, motivators, able to program actions directed to this focus. Therefore, the objective of this study is to investigate the ways found by managers and their team to promote the motivation of teachers in the classroom. For this, interviews were conducted with teachers and managers of schools in the municipality of Júlio de Castilhos/RS. This study is considered relevant because being a teacher is
\end{abstract}


V. 13, n. 1: 2017.

one of the professions that had the most increase of tasks in recent times and the motivation is linked directly with this profession. It is noticed that the results are pertinent, because it refers us to the understanding of the importance of motivation in the school environment, thus reflects in the good performance of students and teachers. Given this, it is evident the great importance that motivation has in the teaching and learning process and, mainly, the motivation of the management team that can positively influence this process.

Key-words: Motivation. Management. Teachers.

\section{INTRODUÇÃO E CONTEXTUALIZAÇÃO DA PESQUISA}

São muitos os questionamentos que levantamos sobre o fenômeno educativo em busca de algumas respostas que nos ajudem a resolver problemas complexos da nossa atualidade, pois na era do conhecimento, como é conhecida a nossa época, a educação é o baluarte da evolução da humanidade. Dessa forma, tem um considerável papel no auxílio na melhoria da vida das pessoas, na diminuição das desigualdades.

Quando se pensa o que é ser um professor do século XXI, logo nos remetemos às mudanças constantes e velozes que acontecem ao nosso redor. Temos certeza de que o maior desafio dos gestores da atualidade é a motivação, sendo um assunto fascinante, por isso justifica-se a escolha deste tema para abordar no projeto de pesquisa, já que a motivação foi e está sendo o principal estímulo para lecionar.

A propósito, no atual contexto educacional, a legislação vigente propõe a Gestão Democrática como paradigma para ser implementada nas instituições escolares, uma vez que a equipe gestora tem um grande desafio de manter os professores sempre motivados para mais um dia de trabalho.

A motivação para os professores é um tema que sempre me atraiu, sabemos que somente um professor motivado poderá exercer suas funções de maneira realmente produtiva e assim poderá motivar seus alunos no processo ensino e aprendizagem.

Para mobilizar uma equipe de trabalho, o gestor deve descobrir o que desperta a motivação de seus professores, funcionários, ou seja, na sua equipe de trabalho.

A apresentação deste estudo está organizada da seguinte forma: no primeiro capítulo apresentamos os referenciais teóricos, que deram o respaldo para esta pesquisa.

No segundo capítulo, é apresentado o desenho da pesquisa, mostrando os objetivos da mesma, os procedimentos metodológicos para fazer a coleta de dados. 
V. 13, n. 1: 2017.

No terceiro capítulo, a análise é o foco principal e, lá, verifica-se qual o papel dos gestores e professores para serem motivados em relação ao seu trabalho na escola.

Por fim, as dimensões conclusivas em que buscamos compreender sobre o processo de motivação dos professores e da equipe gestora, por meio de leituras dos autores que dão sustentação teórica ao estudo e aos questionários respondidos por professores e pela equipe gestora das escolas entrevistadas.

\section{FUNDAMENTAÇÃO TEÓRICA}

No decorrer deste trabalho, procura-se debater sobre a motivação no âmbito escolar, convidando o leitor a se deixar conquistar pelo tema no decorrer das linhas. Dessa forma, procura-se sistematizar o que é motivação, como ser motivado e motivar os alunos, pois muitas atividades humanas dependem da motivação, trabalho, esporte, lazer entre outros.

\subsection{Gestão escolar}

Os termos Gestão e Administração têm origem latina - gerere administrare. O primeiro termo significa governar, conduzir, dirigir. O segundo tem um significado mais restrito, gerir um bem, dependendo os interesses daquele que possui, constituindo-se em uma aplicação de gerir.

De acordo com Andrade (2001), a palavra gestão em seu sentido original, vem do termo latino "gerere" que expressa à ação de dirigir, de administrar e de gerir a vida, os destinos, as capacidades das pessoas e as próprias coisas que lhes pertencem ou que delas fazem uso.

Segundo o autor, uma parcela da sociedade compreende gestão como sendo uma função burocrática destituída de uma visão humanística, como ação voltada à orientação do planejamento, da distribuição de bens e da produção desses bens. É relevante perceber, também, que a prática administrativa não se dá de forma isolada, descontextualizada e individual, ela acontece no grupo e para o grupo, implicando decisões coletivas e organizadas.

Gestão lembra gestação, gerir, dar a vida, e como tal, nos agrada, porque, em se tratando da escola, nosso objetivo principal é fazer com que a vida dos seres humanos que passam por ela (escola) se torne mais promissora, mais digna, mais justa, mais humana. Isto para nós é mais viver, mais gerir, é mais felicidade. Nesse sentido, gestão vai além do seu conceito primeiro que diz respeito à ação de 
V. 13, n. 1: 2017.

dirigir, administrar. Existem vários tipos de gestão, entre elas a gestão escolar que o tema do presente trabalho.

O conceito de Gestão Escolar relativamente recente é de extrema importância, na medida em que desejamos uma escola que atenda às atuais exigências da vida social: formar cidadãos, oferecendo, ainda, a possibilidade de apreensão de competências e habilidades necessárias e facilitadoras da inserção social.

A exigência de uma Gestão Escolar genuinamente democrático-participativa provoca um debate e embate entre práticas e metodologias de diferentes agentes educativos. Coloca em questão políticas públicas, especificamente no que tange à educação e evidencia a exigência de uma grande marcha Freireana, com o objetivo de buscar o sentido da vida que foi expropriada e privatizada ao longo dos tempos em diversas sociedades humanas.

O pensamento de Paulo Freire reflete o que a sociedade deve buscar em termos de educação voltada para políticas democráticas favorecendo a inclusão social, deixando de lado uma gestão dominadora que, infelizmente, ainda presenciamos muito no nosso cotidiano. A falta de democracia piora a situação das escolas. É importante que o gestor se preocupe com a motivação de todos no ambiente escolar. Quando há interesse e ajuda na união de todos por parte, principalmente, dos gestores, realmente, haverá uma política de paz, amor e, consequentemente, a inclusão social. Portanto, Paulo Freire com a sua luta por uma política educacional de inclusão, colocou uma semente que germinará no futuro de nosso país servindo de exemplo para outros países e outras gerações.

A opção por uma Gestão Escolar com base no princípio democrático participativo evidencia a natureza da escola como espaço público, de liberdade, expressão da diversidade e democratização. Gestão Escolar com base nesse princípio não escapa de condição histórica em que tempos e espaços dos mais complexos.

A gestão participativa na escola, de acordo com Luck (2010, p.33), ocorre quando os professores discutem e analisam a problemática pedagógica que vivem em conjunto com a organização escolar, assim os problemas e as situações desejadas são apontados pelo próprio grupo e não pela equipe diretiva. Já uma gestão democrática caracteriza-se pela superação da hierarquia, a partir desta superação, as realizações passam a ser coletivas, em um processo de permanente reconhecimento de direitos e deveres.

Assim, esses dois tipos de gestão - participativa e democrática - redefinem o papel do educador, demandando uma orientação integrada e interativa na sala de aula. Com isso, o professor 
V. 13, n. 1: 2017.

gestor promove o aprendizado dos alunos de uma maneira diferente, enfatizando os valores que foram esquecidos com passar dos tempos.

Nos dias de hoje, a escola é vista como responsabilidade de todos, pois a sociedade demanda uma escola competente, com uso eficiente de recursos e com bons resultados de aprendizagens pelos alunos. Nesse sentido, evidencia-se a forma democrática e participativa que deve assumir a gestão escolar, ensejando que os sistemas de ensino possam organizar e adaptar a gestão pública escolar, conforme o contexto em que ela está inserida.

A escola é uma organização que sempre precisou mostrar resultados referentes ao aprendizado do aluno, com isso é de grande importância à presença de gestores que atuem como líderes, capazes de implantar ações direcionadas para esse foco. A liderança é inerente à dinâmica que envolve ensino e aprendizagem, interessante verificar como o conceito de gestão escolar evoluiu com o passar dos anos e, hoje, é possível pensar em gestão no sentido de gerir uma instituição escolar, desenvolvendo estratégias no cotidiano com a finalidade de uma democratização da gestão educacional.

Conforme apontado por Luck (2008, p. 11), gestão escolar constitui uma dimensão e um enfoque de atuação que objetiva promover a organização, a mobilização e a articulação de todas as condições materiais e humanas necessárias para garantir o avanço dos processos sócio educacionais dos estabelecimentos de ensino, orientadas para a promoção efetiva da aprendizagem pelos alunos. E, assim, torná-los capazes de enfrentar adequadamente os desafios da sociedade globalizada e da economia centrada no conhecimento.

Menezes e Santos (2002 p. 13) definem a Gestão Escolar como expressão relacionada à atuação que objetiva promover a organização, a mobilização e a articulação de todas as condições materiais e humanas necessárias para garantir o avanço dos processos socioeducacionais dos estabelecimentos de ensino orientados para a promoção efetiva da aprendizagem pelos alunos.

Nos dias de hoje, podemos ver o perfil do gestor, que tem a necessidade de repensar alguns fundamentos educacionais quebrando novos paradigmas, como relação à interdisciplinaridade pedagogia de projetos, temas geradores de pesquisa em sala de aula, construção do conhecimento e habilidades.

Sendo assim, o professor não pode alienar-se quando está em pauta a educação no Brasil, é fundamental que ele tenha o apoio e o acompanhamento dentro da organização escolar para que, como sujeito consciente de seu papel social, promova mudança em si e no ambiente escolar. Para 
V. 13, n. 1: 2017.

isso, a gestão escolar deve levar em conta a legislação que estabelece os princípios da educação e os deveres do estado em relação à educação escolar pública - a LDB.

\subsection{Gestão escolar e a LDB}

Política pública é uma expressão que visa a definir uma situação específica da política. A melhor forma de compreendermos essa definição é partimos do que cada palavra, separadamente, significa. Política é uma palavra de origem grega, politikó, que exprime a condição de participação da pessoa que é livre nas decisões sobre os rumos da cidade, a pólis. Já a palavra pública é de origem latina, publica, e significa povo, do povo.

Assim, política pública, do ponto de vista etimológico, refere-se à participação do povo nas decisões da cidade, do território. Porém, historicamente essa participação assumiu feições distintas, no tempo e no lugar, podendo ter acontecido de forma direta ou indireta (por representação). De todo modo, um agente sempre foi fundamental no acontecimento da política pública: o Estado.

A discussão acerca das políticas públicas tomou nas últimas décadas uma dimensão muito ampla, haja vista o avanço das condições democráticas em todos os recantos do mundo e a gama de arranjos institucionais de governos, que tornou-se necessário para se fazer a governabilidade. Entende-se por governabilidade as condições adequadas para que os governos se mantenham estáveis. São essas condições adequadas, enquanto atitudes de governos (sejam eles de âmbito nacional, regional/estadual ou municipal), que caracterizam as políticas públicas.

A Constituição Federal de 1988, nossa Carta Magna, estabelece, no seu artigo 206, que a forma de gestão da educação brasileira deve ser a democrática e participativa, como atesta o inciso VI do referido artigo:

Art.206 - O ensino será ministrado com base nos seguintes princípios: (Alterado pela EC000.019-1998): I - igualdade de condições para o acesso e permanência na escola; II - liberdade de aprender, ensinar, pesquisar e divulgar o pensamento, a arte e o saber; III - pluralismo de ideias e de concepções pedagógicas, e coexistência de instituições públicas e privadas de ensino; IV - gratuidade do ensino público em estabelecimentos oficiais; obs.dji.grau.2: Art. 242, Disposições Constitucionais Gerais - CF; obs.dji.grau.5: Cobrança de Taxa de Matrícula nas Universidades Públicas - Constitucionalidade - Súmula Vinculante $\mathrm{n}^{\circ} 12$ - STF; V valorização dos profissionais da educação escolar, garantidos, na forma da lei, planos de carreira, com ingresso exclusivamente por concurso público de provas e títulos, aos das redes públicas; (Alterado pela EC-000.053-2006). VI - gestão democrática do ensino público, na forma da lei; VII - garantia de padrão de qualidade; VIII - piso salarial profissional nacional 
V. 13, n. 1: 2017.

para os profissionais da educação escolar pública, nos termos de lei federal. (Acrescentado pela EC-000.053-2006); obs.dji.grau.4: Ensino; Ordem Social

Existem em nosso país diversas políticas públicas aplicadas à educação pública nos níveis federais, municipais e estaduais de ensino. Dentre essas, a LDB, Lei de Diretrizes e Bases, número 9.394, promulgada em 20 de dezembro de 1996, que estabelece as diretrizes e bases da educação nacional, definindo e regularizando o sistema de educação brasileiro com base nos princípios presentes na Constituição Federal. A primeira Lei de Diretrizes e Bases foi criada em 1961. Uma nova versão foi aprovada em 1971 e a terceira, ainda vigente no Brasil, foi sancionada em 1996.

Todo o sistema de educação no Brasil é legitimado por leis específicas que tentam viabilizar políticas que possam contribuir para o crescimento da educação pública no país. Essas leis estão contidas na LDB (Leis de Diretrizes e Bases/1996). De acordo com elas a gestão da educação no Brasil está organizada em sistemas de ensino federal, municipal e estadual.

Na LDB, Art. 12, Incisos I a VI, estão as principais delegações que se referem à gestão escolar no que diz respeito as suas respectivas unidades de ensino: Os estabelecimentos de ensino, respeitadas as normas comuns e as do seu sistema de ensino, terão a incumbência de:

I - elaborar e executar sua proposta pedagógica; II - administrar seu pessoal e seus recursos materiais e financeiros; III - assegurar o cumprimento dos dias letivos e horas-aula estabelecidas; IV - velar pelo cumprimento do plano de trabalho de cada docente; $\mathrm{V}$ - prover meios para a recuperação dos alunos de menor rendimento; VI - articular-se com as famílias e a comunidade, criando processos de integração da sociedade com a escola;

Para a LDB, o planejamento, a elaboração e a execução de uma proposta pedagógica é a principal das atribuições das unidades de ensino, devendo ela, assim, na sua gestão trilhar um caminho orientado por esta finalidade. (VIEIRA, 2008, p. 43).

Dentre os sete incisos anteriormente citados é interessante observar a dimensão da gestão escolar na relação com a comunidade escolar. A relação escola-comunidade é uma relação em que ambas requer a visibilidade e transparência da participação tanto da escola quanto da comunidade no processo de educação de qualidade.

A gestão escolar tem finalidades jurídicas e todas as suas ações são legitimadas por elas, a gestão democrática também tem sua legitimação na constituição e na LDB. No seu artigo 18, a democratização da gestão se reduz a um ideal de orientação de atividades de escolas e universidades 
V. 13, n. 1: 2017.

e ao incentivo à participação da comunidade. Desse modo, a gestão democrática constitui princípio

fundamental da organização e da administração das instituições públicas de ensino, compreendendo:

I - a existência de mecanismos de co-participação na gestão das instituições de ensino, com representação dos segmentos que a integram, incluídos, no caso das instituições destinadas á educação e ao ensino de crianças e adolescentes, os pais ou responsáveis; $1^{\circ}$ - o cumprimento do disposto neste artigo dar-se-á com observância dos seguintes preceitos: I - existência de órgãos colegiados e conselhos escolares, com competência sobre o conjunto de todas as atividades desenvolvidas pela instituição; III - avaliação permanente da qualidade de serviços prestados e dos resultados das atividades educacionais oferecidas à sociedade; V - utilização de métodos participativos para a escolha de dirigentes, ressalvado o provimento de cargos por concurso público; VI - incentivo para a criação de associações de profissionais do ensino, alunos, ex-alunos e pais, além das de caráter acadêmico, assegurada sua participação nos processos decisórios internos das instituições.

Todas as atividades desenvolvidas pelas instituições públicas visam ao avanço dos indicadores nos sistemas de avaliação e a contribuição das comunidades escolar (diretores, coordenadores, professores, alunos, ex-alunos, pais etc).

A gestão democrática é definida com os princípios de integração do sistema/escola com a família, comunidade e sociedade, descentralização, participação democrática no processo educacional, maioria dos professores em colegiados e comissões (SAVIANI, 1997).

Mas, a gestão democrática não está restrita apenas as unidades escolares. Ela é um valor público definido em forma de lei que remete tanto a gestão escolar quanto, no nível mais geral, à gestão educacional. A gestão democrática é um eixo importantíssimo de ações públicas. Para Rosar (1992, p. 12), isso significa que:

[...] a redefinição da estrutura de poder, desde o nível macro do Ministério da Educação na sua forma de organização e funcionamento, até o nível micro de cada escola. As ações do MEC deveriam está adequadas às deliberações de um Fórum Nacional de Educação que pudesse definir, a partir de amplo debate nacional, as diretrizes político-pedagógicas, as prioridades educacionais, a garantia de recursos para todos os níveis de ensino considerados como um todo, e as formas de avaliação dos mesmos, com a participação de diversos setores sociais.

A LDB regulamenta a gestão democrática do ensino público em geral, contribuindo de forma transparente para que as leis sejam aplicadas na educação básica oferecendo autonomia às unidades federativas para um planejamento adequado as pretensões de cada unidade.

Vivemos diante de diversas dificuldades apresentadas pela escola na sociedade, desde as políticas públicas implementadas até os conflitos existentes internamente. Na gestão é importante a 
V. 13, n. 1: 2017.

participação de todos os agentes que contribuem de forma direta ou indireta nos processos de organização da escola. O êxito escolar dos alunos está inteiramente relacionado com a gestão da escola. Para VIEIRA (2007), [...] o sucesso de uma gestão escolar, em última instância, só se concretiza mediante o sucesso de todos os alunos. Daí porque é preciso manter como norte a gestão voltada para uma comunidade de aprendizes, que pode ser conduzida de diferentes formas e, uma delas, acredita-se, ser a motivação.

\subsection{Gestão escolar e motivação}

Dentre os múltiplos significados dados à motivação, pode-se afirmar que motivação é um impulso que faz com que as pessoas ajam para atingir seus objetivos. Ela envolve fenômenos emocionais, biológicos e sociais e é um processo responsável por iniciar, direcionar e manter comportamentos relacionados como cumprimento de objetivos.

Segundo Guimarães (2009), motivação é um tópico muito estudado pela psicologia, para saber o que faz com que as pessoas se comportem da maneira como se comportam, de onde vem à motivação, e o que ocorre quando as pessoas não são motivadas. A motivação é avaliada em certos tratamentos psicológicos em que é imprescindível medir a disposição real que um indivíduo tem para iniciar um tratamento.

A motivação é um elemento essencial para o desenvolvimento do ser humano, pois sem ela é muito mais difícil cumprir algumas tarefas. É muito importante ter motivação para estudar, para fazer exercício físico, para trabalhar e para tantas outras coisas que fazem parte da vida das pessoas.

Conforme Guimarães, (2009), o processo de motivação pode acontecer por meio de uma força interior, ou seja, cada pessoa tem a capacidade de se motivar ou desmotivar, também chamada de automotivação ou motivação intrínseca. Há também a motivação extrínseca, que é aquela gerada pelo ambiente que a pessoa vive, o que ocorre na vida dela influencia em sua motivação.

Acredito que somente um professor motivado poderá exercer suas funções de maneira realmente produtiva e somente assim poderá motivar seus alunos no processo de ensino e aprendizagem. As palestras motivacionais para professores fortalecem a autoestima ao aflorar os motivos que impulsionam os professores a ministrar aulas com entusiasmo. 
V. 13, n. 1: 2017.

Muitos gestores reclamam da falta de motivação da e sua equipe, alguns buscam justificativas no salário baixo, outros no comportamento inadequado de alguns alunos, mas isso foge da alçada dos gestores, entretanto não podemos encontrar justificativas nesses fatores elencados acima.

Para mobilizar uma equipe de trabalho o gestor deve descobrir o que desperta a motivação nos professores e funcionários, não podendo esquecer que muitas vezes o desânimo da equipe de trabalho origina-se da insatisfação dos gestores, pois é muito comum que a equipe gestora imprima o clima dominante na escola. Como por exemplo, eventos especiais, como congressos, seminários, curso de atualização e dinâmicas mirabolantes não garantem a motivação dos professores, mas sim o dia a dia de trabalho, que faz com que todos percebam a importância da sua função para a aprendizagem dos alunos. O professor sempre que é chamado para participar da elaboração de funções dentro da escola se sente valorizado.

Segundo John Adair (2001), no seu livro Liderança e Motivação, "Cinquenta por cento da motivação vem de dentro da pessoa e 50 por cento provém de seu ambiente, em especial da liderança encontrada lá”. Compreende-se, diante disso, que só é possível motivar uma equipe de trabalho se a pessoa em si, nesse caso a gestão escolar, estiver motivada. Além do mais, os discursos dos professores são frequentes sobre a motivação tanto dos alunos, quanto dos próprios professores.

De acordo com Luck (2008, p.15), uma das maiores características de um gestor escolar é a motivação, portanto é por meio dela que conseguimos atingir os objetivos propostos, não ter medo de risco e de fracasso, enfrentando-os como uma possibilidade natural a todas as relações humanas. $\mathrm{O}$ gestor deve ter uma boa liderança de comunicação, sabendo interagir com sua equipe de trabalho de modo equilibrado e positivo, valorizando o potencial de cada professor.

Bzuneck $(2009$, p.9) ressalta que a motivação é entendida ora como um conjunto de fatores psicológicos, ora como um processo e destaca que, nas concepções contemporâneas, a metáfora de investimento pessoal contribui para que se compreenda o que seja motivação. Devemos investir nos nossos recursos pessoais para conseguirmos ter habilidades para encontrar a motivação na labuta diária.

Outro fator que está ligado com a motivação do professor é a sua qualidade de vida, é de suma importância a saúde do profissional, ou seja, um professor que está com sua saúde em dia certamente terá muito mais ânimo de efetuar seu trabalho do que um profissional com sua saúde debilitada. Dessa forma, a motivação e a qualidade de vida andam juntas, pois passam a serem fatores relevantes no âmbito profissional. 


\section{13, n. 1: 2017.}

Ao falarmos em motivação no processo de aprendizagem escolar, é extremamente relevante salientar a relação professor- aluno, pois o modo como esse relacionamento se dá vai dimensionar e direcionar a questão da motivação. Um professor, consciente de seu papel, sabe que sua tarefa é orientar o aluno em seu aprendizado, tornando-o mais crítico, buscando sempre seu êxito e não seu fracasso.

Referindo-se à motivação em sala de aula, nas palavras de Tapia e Fita (1999, p.100) quando afirmam que "é necessário que o professor transmita valores de forma explícita. Devemos lutar contra a tendência de deixar isso exclusivamente nas mãos dos especialistas, professores de religião, ética. Essa tarefa deve ser assumida por todos os professores".

Em sala de aula é necessário levar em conta as peculiaridades que diferenciam cada um, pois a motivação do aluno está relacionada diretamente com o contexto em sala de aula, não esquecendo que no ambiente escolar as atividades dos alunos são desenvolvidas em grupos. Visto que o professor é um profissional como outro qualquer do ponto de vista trabalhista, mas tem uma função, uma missão que é o seu diferencial, ele exerce grande influência sobre a formação da personalidade e do caráter de seus alunos. Seu modo de agir com ele, de interagir com a turma durante as aulas, vai transmitirlhe muito mais do que o simples conteúdo das disciplinas e pode deixar marcas para o resto de suas vidas. Essas marcas podem ter um cunho positivo ou negativo.

Quanto maior for a afinidade entre os professores e alunos, melhor será a motivação do processo de ensino e aprendizagem, pois mais facilmente os alunos compreenderão o sentido de estudar o que está sendo apresentado pelo professor e terão a curiosidade de buscar novas informações que possam complementar a aula, tornando-a um momento de aprendizagem dinâmica para ambos, aluno e professor.

A aprendizagem, apesar de ser um processo individual, somente ocorre com as interações e intermediações sociais, no coletivo, o espaço privilegiado para aprendizagem é a escola, na sala de aula. A realidade educacional é um campo de possibilidades e requer que o professor faça uso de todas as suas competências e de suas habilidades pedagógicas, entre elas a sua capacidade de comunicação, para motivar seus alunos para a aprendizagem, mediar conflitos, mobilizar os alunos para o esforço e a disciplina mental, promover a cooperação e a solidariedade.

Motivar o aluno significa motivá-lo para a aprendizagem e os estudos, função da escola e do professor. Um aluno que quer aprender dependerá muito pouco da competência da escola, diferentemente de um aluno com problemas de motivação, pois a desmotivação é um problema muito 
V. 13, n. 1: 2017.

sério e com consequências negativas na vida e na formação dos estudantes. Diante dessas discussões considerou-se que a motivação, influencia nos resultados do ensino e aprendizagem e como professores e equipe gestora alcançam sucesso na sua escola.

\section{DELINEAMENTODA PESQUISA}

No capítulo anterior foram apresentados os referenciais teóricos que deram sustentação à pesquisa, viabilizando a análise crítica e reflexiva da questão estudada. Neste capítulo delimita-se o problema, explicitando os objetivos, procedimentos e abordagem metodológica e descrevendo o espaço de realização da investigação, cujo foco é a comunicação entre pais, professores e alunos frente ao processo de aprendizagem.

\subsection{Delimitação do Problema}

Quais são as formas encontradas pelo gestor e sua equipe para motivar o (a) professor (a) em sala de aula?

\subsection{Objetivos da Pesquisa}

\subsubsection{Objetivo Geral}

Investigar quais são as formas encontradas pelo gestor e sua equipe para promover a motivação dos professores em sala de aula.

\subsubsection{Objetivos Específicos}

Verificar as ações/estratégias pelo gestor e sua equipe que favorecem a motivação dos professores para o trabalho em sala de aula; Analisar de que forma essas ações/estratégias interferem na sala de aula.

\subsection{Procedimentos Metodológicos}

\subsubsection{Metodologia da Pesquisa}


V. 13, n. 1: 2017.

Foi realizada uma pesquisa qualitativa, que segundo Minayo (2008), é um tipo de pesquisa que trabalha com o universo de significados, motivos, aspirações, crenças, valores e atitudes que correspondem a um espaço mais profundo das relações. Desse modo, foram aplicados questionários, sendo uma para equipe da gestão e outra para os professores em escolas.

E, também do tipo exploratória que, para Lakatos (2003, p.188), são investigações de pesquisa empírica com o objetivo de formular questões, com tripla finalidade: desenvolver hipóteses, aumentar a familiaridade do pesquisador com o ambiente, fato ou fenômeno, para uma pesquisa futura mais precisa ou, ainda, para modificar conceitos.

\subsubsection{Os procedimentos para coleta de dados e os instrumentos de pesquisa}

Para alcançar os objetivos da pesquisa, utilizou-se como procedimento técnico para coleta de dados a realização de entrevistas individuais, semiestruturadas, uma para equipe gestora e outra para os professores, de duas escolas no município de Júlio de Castilhos, a Escola Estadual Dolores Paulino e a Escola Municipal Visconde de Mauá.

Minayo (2008) caracteriza como semiestruturada a entrevista que combina perguntas fechadas e abertas, em que o entrevistado tem a possibilidade de discorrer sobre o tema proposto sem perder a essência da pesquisa. As entrevistas foram realizadas a partir de perguntas (apêndice a e b), preparadas no início dos estudos.

\subsection{O Contexto de Pesquisa}

No município de Júlio de Castilhos tem cinco escolas municipais e sete estaduais. Para a realização deste trabalho, optou-se por duas dessas escolas, sendo ambas da periferia, uma municipal e outra estadual, para poder fazer um paralelo entre elas. As escolas são as seguintes: Escola Estadual de Ensino Fundamental Dolores Paulino e Escola Municipal de Ensino Fundamental Visconde de Mauá. Esta foi fundada em 15 de agosto de 1958 e é composta por 158 alunos, 27 professores e 3 componentes da equipe gestora. Aquela foi fundada em 18 de novembro de 1958 e é composta por 240 alunos, 14 professores e cinco componentes da equipe gestora. 
V. 13, n. 1: 2017.

\subsubsection{Os sujeitos participantes da pesquisa}

A pesquisa foi realizada em escolas de ensino fundamental, localizadas na periferia do município, com alunos oriundos de baixa renda, grande índice de vulnerabilidade social. Para isso, os questionários foram respondidos por professores e pela equipe gestora das escolas.

$\mathrm{Na}$ Escola Estadual de Ensino Fundamental Dolores Paulino, quatro professores e quatro gestores responderam ao questionário, sendo que vários docentes em ambas as escolas não quiseram ser identificados. A seguir a representação gráfica dos sujeitos participantes:

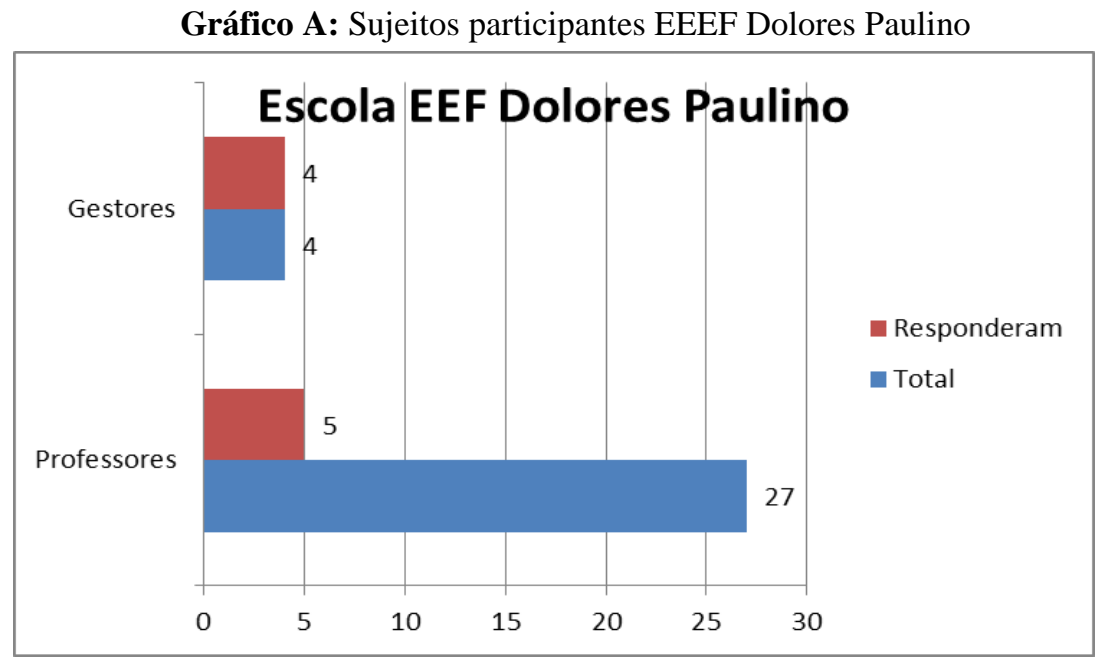

Fonte: Elaborado pela(s) autora(s)

Na Escola Municipal de Ensino Fundamental Visconde de Mauá, dos quatorze professores somente cinco responderam e, da equipe gestora, três gestores responderam ao questionário.

Gráfico B: Sujeitos participantes EMEF Visconde de Mauá 
V. 13, n. 1: 2017.

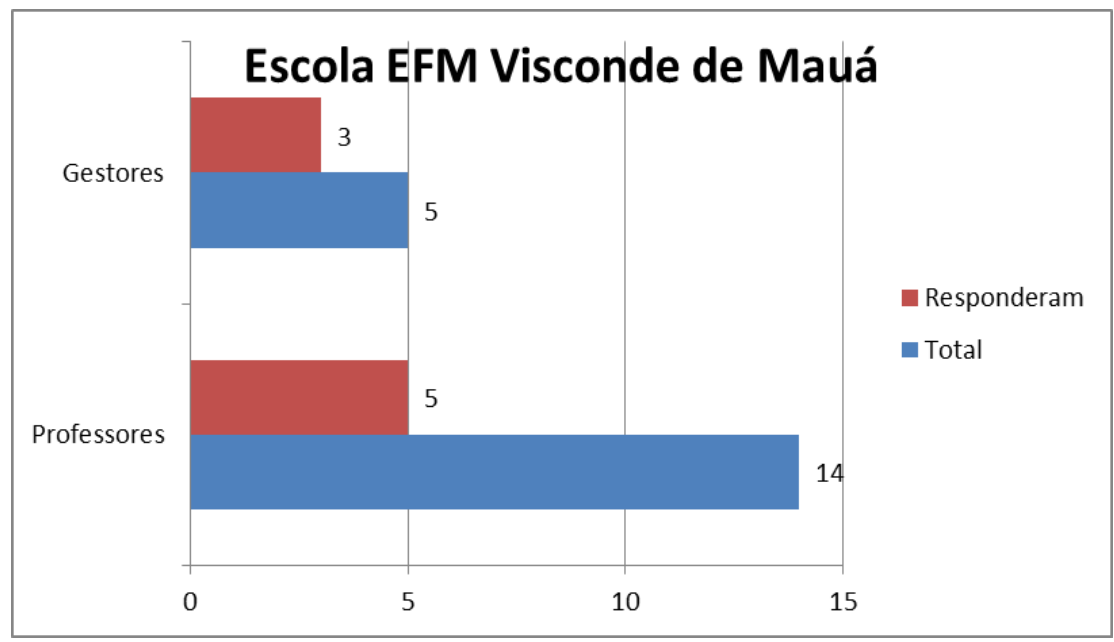

Fonte: Elaborado pela(s) autora(s)

\subsubsection{Análise e interpretação dos dados}

Após a leitura das entrevistas, foram organizados os dados, a análise das respostas, estabelecendo uma relação e comparação dos depoimentos com respaldo no referencial teórico levantado.

\section{APRESENTAÇÃO E ANÁLISE}

O foco principal da análise foi verificar qual o papel dos gestores e professores para serem motivados em relação ao seu trabalho na escola.

O questionário foi composto de 5 questões, sendo que as questões 1,2 e 3 foram direcionadas tanto para gestores como para professores.

A Escola Municipal de Ensino Fundamental Visconde de Mauá é composta de vinte e sete professores e três gestores, sendo que cinco professores responderam ao questionário proposto, e dos três gestores somente um respondeu todo o questionário, pois os demais não responderam às questões quatro e cinco que se encontravam no verso da folha, embora tenham sido avisados que essas questões estariam lá. Na Escola Estadual de Ensino Fundamental Dolores Paulino composta por quatorze 
V. 13, n. 1: 2017.

professores e cinco gestores, somente quatro professores e quatro gestores responderam às questões. Nesta escola todos responderam as questões quatro e cinco.

As referidas questões apresentavam os seguintes questionamentos:

1. O que você entende por motivação?

2. Você é uma pessoa motivada? Por quê?

3. Como você vê a motivação no seu ambiente escolar?

A seguir os resultados obtidos por escola:

\section{a) ESCOLA MUNICIPAL DE ENSINO FUNDAMENTAL VISCONDE DE MAUÁ}

Nessa escola obtivemos como resposta:

Para a questão 1: "A motivação é interna precisamos estar bem para motivar outras pessoas"; "A motivação é intrínseca ao ser humano, faz com que as pessoas confundam seus objetivos com os da instituição em que atua"; "É a vontade que temos de fazer algo com alegria e prontidão"; "Predisposição para realizar as atividades laborais e sociais"; "Impulso que as pessoas agem para superar obstáculos, motivação envolve anseios, esperanças, sonhos, é o sentido que damos as atividade que realizamos"; "É a vontade de fazer com que o aluno cresça como pessoa com teus ensinamentos"; "Motivação é para mim um estado de espírito, precisamos estar bem pra estarmos motivados e também motivar"; "Buscar recursos que instigam o gosto por uma determinada atividade".

Para a questão 2: "Sim, para trabalharmos com pessoas precisamos estar motivadas, pois cada dia é um desafio"; "Sim, porque gosto do que faço"; "Acho que sim, tenho sempre boa vontade, mas estou em contagem regressiva para terminar a minha carreira no magistério público estadual e municipal”; "Parcialmente, penso que a motivação depende de vários fatores como realização pessoal e financeira"; "Sou muito motivada, amo o que faço, é através da motivação que desempenho o meu trabalho, missão de ensinar"; "Sim, pois todo dia é um desafio", "Sim, porque adoro o trabalho que realizo como professora"; "Sim, pois amo o que faço."

Para a questão 3: "Penso que dentro do possível estamos bem, dificuldades com as diferentes juventudes adversidades do dia a dia"; "Crescente"; "Não, os alunos estudam pouco, somente alguns 
V. 13, n. 1: 2017.

conseguem ter vontade em vencer no dia a dia"; "Acredito que nós professores estamos pouco motivados"; "Muito boa! As reuniões são produtivas e interessantes, bom clima para o trabalho, supervisora disponível e justa"; "Apesar das dificuldades as pessoas enfrentam os desafios com otimismo"; "presente na maioria dos colegas e alunos".

\section{b) ESCOLA ESTADUAL DE ENSINO FUNDAMENTAL DOLORES PAULINO}

Nessa escola obtivemos como resposta:

Para a questão 1: "É gostar do que faz, ter interesse se envolver, buscar"; "Motivação é um sentimento que faz com que os indivíduos deem o melhor de si, façam o possível para conquistar o que almejam, a motivação é um elemento essencial para o desenvolvimento do ser humano"; “ Gostar do que faz e procurar sempre melhorar, buscar dedicação, qualificação, inovação”; “ Motivação é o motivo pelo qual estamos preparados para uma determinada ação, com um comprometimento para realizá-lo"; "Motivação é um instrumento positivo para a construção do conhecimento do educando"; "Motivação é um impulso que faz com que as pessoas deem o melhor de si para alcançar os seus objetivos"; "É uma função intrínseca no ser humano, que deve ser sempre renovada, procurada, buscada"; "Uma força interna que nos inspira a seguir em frente, contornando as adversidades".

Para a questão 2 : "Sim, porque gosto do que eu faço"; "Sim, sou motivada, porque sou feliz, gosto do que faço, enxergo o mundo com outros olhos, conquisto resultados, supero obstáculos, sou persistente e acredito nos meus sonhos"; Na maioria das vezes, pois faço o que eu gosto e estou constantemente procurando me atualizar e melhorar meu desempenho, buscando inovar e qualificar"; "Acredito que sim, pois venho para meu trabalho determinada e com vontade de fazê-lo da melhor forma possível”; "Sim, busco desempenhar minha profissão da melhor maneira possível, dando sempre o meu melhor"; "Em parte, penso que para a pessoa estar motivada deveria também ter uma melhor valorização do seu trabalho, melhorias no aspecto físico das escolas para melhor desenvolvimento do trabalho"; "Penso que sim, por necessidade, é preciso sempre encontrar motivação para tudo o que vamos fazer, assim tudo fica mais agradável”; "Tudo depende da situação em que me encontro, mas, na maioria das vezes, sim”.

Na questão 3: "Alguns sempre motivados, procurando, digo, buscando novidades, envolvidos, coerentes com a fala e a prática, disponíveis, enquanto outros um tanto desmotivados, 
V. 13, n. 1: 2017.

parece que não mais acreditando no quanto a educação pode transformar, ou melhor, fazendo porque tem o que fazer"; "As pessoas são diferentes umas das outras, o que motiva uma pessoa em um certo momento pode não motivar a outra no mesmo instante. Na maioria, posso considerar um time envolvido, trazendo ideias, envolvidos no processo, me respeitam como gestora, pois procuro reconhecer o trabalho bem realizado"; "Em parte, alguns professores se entusiasmam com seus afazeres, se dedicam e tentam passar para os alunos. No entanto o grupo não é coeso, alguns fazem apenas o " arroz com feijão" o fazer por fazer"; "Cada um procura no todo uma vontade de deixar o ambiente agradável, e essa procura faz com que todos se preparem, fazendo com que a motivação absorva à todos", "Um fortalecimento de base, para conquistarmos nossos objetivos, que é chegar na aprendizagem do aluno"; "Vejo que precisa de uma melhor atenção da mantenedora e dos governantes em oferecer um melhor ambiente de trabalho, aspecto físico, e uma verdadeira valorização do professor"; "Precisa ser buscada sempre, pois muitas vezes nossa tarefa fica difícil, convivemos diariamente com muitas juventudes, temos diversas funções, problemas, no entanto, como educadores não podemos entrar em uma sala de aula desmotivados, ali mais de uma pessoa espera por nós, precisamos lembrar sempre disso"; "No ambiente escolar procuro motivar-me sempre para passar isso para meus alunos".

Os professores escola MEF Visconde de Mauá responderam ao questionário, sendo que vários docentes não quiseram ser identificados. Eles afirmam que a motivação está ligada a seu estado de espírito, que envolve anseios, esperanças, sonhos, predisposição para realizar as atividades laborais.

Para os gestores, a motivação está ligada à vontade de fazer algo novo com alegria e prontidão, pois segundo eles a motivação é intrínseca ao ser humano.

Os docentes da Escola Estadual Dolores Paulino comentam que a motivação é um impulso que faz com que as pessoas deem o melhor de si para alcançar os seus objetivos, instrumento positivo para construção do conhecimento educacional.

Os gestores dessa escola defendem que motivação é gostar do que se faz, ter interesse, envolver-se com as questões da escola. Para eles, motivação é um sentimento que faz com que o individuo dê o melhor de si, ou seja, é um elemento essencial para o desenvolvimento do ser humano.

Diante disso, conclui-se que professores e gestores, em sua maioria, fazem o que gostam, com isso, a motivação vem junto com o gosto pela atuação n o magistério. Segundo o público que respondeu o questionário, é preciso que as aulas sejam ministradas com alma e não apenas com a 
V. 13, n. 1: 2017.

cabeça, que o docente tenha consciência do compromisso que se tem com os alunos e não só com o conteúdo. Além disso, é mister acreditar no que se faz.

Para Luck (2002 p. 46), a motivação é a chave que abre a porta para o desempenho com qualidade, em situação tanto no trabalho como atividades de lazer e também em atividades pessoais e sociais. Ainda, segundo a autora, essa valorização é uma tarefa que demanda percepção, observação e comunicação para conseguir enxergar no outro sua essência como ser humano, não se balizando somente nas competências que o professor apresenta.

Nesse sentido, para a mesma autora, a motivação é um empurrão ou a alavanca que estimula as pessoas a agirem e se superarem. A motivação é, portanto, o processo que mobiliza o organismo para a ação, a partir de uma relação estabelecida entre o meio ambiente, a necessidade e o objeto de satisfação. Isso significa que, na base da motivação, está sempre um organismo que apresenta uma necessidade, um desejo, uma intenção, um interesse, uma vontade ou uma predisposição para agir.

De acordo Bock (1999, p.121), na motivação está também incluído o ambiente que estimula o organismo e oferece o objeto de satisfação. E, por fim, na motivação está incluído o objeto que aparece com a possibilidade de satisfação da necessidade.

Por meio da motivação alcançaremos um resultado satisfatório com nossos alunos, professores e equipe gestora. Estes motivados geram alunos motivados, e o resultado disso é o ensino e aprendizagem alcançados.

As questões 4 e 5 foram diferenciadas. Inicialmente, apresentam-se as respostas aos questionamentos realizados aos gestores.

4. Você realiza alguma ação para promover a motivação do professor em sala de aula?

5. Você acredita que essas ações podem produzir algum efeito no dia a dia da escola? Quais? Por quê?

A seguir os resultados obtidos por escola para as referidas questões:

\section{a) ESCOLA MUNICIPAL DE ENSINO FUNDAMENTAL VISCONDE DE MAUÁ}

Nessa escola obtivemos como resposta pelos gestores:

Para a questão 4: "Sim, várias dinâmicas de grupo". Aqui, cabe ressaltar que os demais gestores "esqueceram" de olhar no verso da folha, como foi explicado ao ser entregue o questionário, 
V. 13, n. 1: 2017.

e deixaram de responder às duas últimas questões. A resposta foi simples e direta, porém não foram elencadas quais dinâmicas foram ou são realizadas.

Para a questão 5: "Sim, harmonia entre o grupo, porque um ambiente aconchegante ajuda a realizar as necessidades humanas.

Aqui, também cabe ressaltar que os demais gestores "esqueceram" de olhar no verso da folha, como foi explicado ao ser entregue o questionário, e deixaram de responder às duas últimas questões. Nessa perspectiva, podemos perceber que ouve uma distância e/ou falta de compreensão da pergunta, pois a resposta não comtemplou a pergunta na sua totalidade, não foi citada quais ações são realizadas, e porque, assim não possibilitando uma análise mais profunda da resposta.

\section{b) ESCOLA ESTADUAL DE ENSINO FUNDAMENTAL DOLORES PAULINO}

Para a questão 4: "A equipe diretiva promove reuniões onde podemos participar e expor nossas angústias, cursos, seminários"; "Sim, invisto bastante em treinamentos, palestras, encontros, cursos, oficinas, possibilitando a eles uma maneira de expressar suas metas e vontades, para que consigam ter conhecimento do que motiva"; "Promovendo cursos e seminários, reuniões e encontros, sugestões de dinâmicas, filmes e músicas, entre outros"; "Com os professores que coordeno, procuro incentivá-los a cada dia dando apoio pedagógico necessário".

Para a questão 5: “Acredito que cada um já tem a motivação dentro de si, já são ou nascem motivados, gostam do que fazem, para estes, o que a escola realiza motiva e ajuda, para outros tanto faz, nada vai mudar"; "Sim, ocorre um comprometimento entre professores, alunos, pais e esta participação mostra que todos, são importantes para a escola, e isto estimula a motivação, quando a pessoa faz, passa a ser importante, e ela torna-se útil"; "Talvez colaborem, mas a motivação inicia, ou seja, vem do interior da cada ser humano, se você quer o pouco é muito, se você não quer nada te empolga"; "Sim, o bem querer pela escola pois, nossos alunos são carentes e precisam de muita atenção".

A seguir, apresentam-se os questionamentos realizados aos professores.

4- A escola em que você trabalha desenvolve algum trabalho para promover a motivação da equipe da escola? Caso realiza, que tipo e como você avalia este trabalho? 
V. 13, n. 1: 2017.

5- As atividades realizadas pela escola interferem no seu dia a dia em sala de aula? De que forma?

\section{a) ESCOLA MUNICIPAL DE ENSINO FUNDAMENTAL VISCONDE DE MAUÁ}

Para a questão 4: "Sim, palestras e encontros dos professores, avalio com satisfatória"; “ Antes das reuniões sempre tem mensagem de otimismo, nas datas importantes os professores sempre são lembrados"; "Palestras, encontros dos professores"; "Sim, dinâmica de grupo, palestras, todos os trabalhos são ótimos", "Sim, bom”.

Para a questão 5: "Não interfere de forma significativa", "Não, para tudo tem o seu tempo, tempo para ensinar em sala de aula, tempo para as atividades e reuniões, sem interferir as atividades de sala de aula", "Não as atividades geralmente envolvem os alunos também", "Sim, de forma muito positiva, vem sempre acrescentar algo a educação, em especial na aprendizagem e formação de cada aluno", "Sim, nos levam a olhar nossa prática com outros olhos".

\section{b) ESCOLA ESTADUAL DE ENSINO FUNDAMENTAL DOLORES PAULINO}

Para a questão 4: "Sim, formações pedagógicas, reuniões etc"; "Sim, procura da melhor forma possível trazer pessoas para falar sobre o assunto para que possa manter o corpo docente o mais motivado possível para o trabalho"; "Sim, através da formação continuada, mensagens, receptividade, esse trabalho é bom e interfere na motivação individual”; "Reuniões pedagógicas".

Para a questão 5: "Sim, através de reflexões, questionamentos, pois pertencemos ao contexto escolar e interfere de forma direta e indireta"; "Em parte, quanto acontecer atividades extra curriculares o espaço para as aulas fica reduzido, e as vezes quando são atividades que envolvem a música, muitas vezes os alunos desviam a atenção nas aulas"; "Sim, ajuda a melhorar nossa auto estima, motiva, incentiva"; "Sim, pois estamos inseridos num mesmo contexto".

Uma das grandes virtudes da motivação é melhorar a atenção e a concentração, nessa perspectiva pode-se dizer que a motivação é a forma que move o sujeito a realizar atividades. Ao sentir-se motivado o indivíduo tem vontade de fazer alguma coisa e se tornar capaz de manter o esforço necessário durante o tempo necessário para atingir o objetivo proposto. Bock (1999, p. 121) afirma que a preocupação do ensino tem sido a de criar condições tais, que o aluno "fique a fim" de aprender. 
V. 13, n. 1: 2017.

Partindo desse contexto, percebe-se que a motivação deve ser considerada pelos professores de forma cuidadosa, procurando mobilizar capacidades e potencialidades dos alunos a este nível.

Torna-se tarefa primordial do professor identificar e aproveitar aquilo que atrai o aluno, o que ele gosta, como modo de privilegiar seus interesses. Bock (1999) ainda ressalta que motivar passa a ser, também, um trabalho de atrair, encantar, prender a atenção, seduzir o aluno, utilizando o que o aluno gosta de fazer como forma de engajá-lo no ensino.

O professor exerce o papel de mediador entre o universo social e o particular do aluno. Para tanto, deve possuir qualidades como: compreensão da realidade em que trabalha, comprometimento, competência no campo teórico de conhecimento em que atua e competência técnica profissional. Porém, tudo isso não adianta se o professor não se sentir motivado a colocar todo seu conhecimento em prática. Nesse sentido, Luck (2002) salienta que

o professor é a figura central na formação dos educandos. É ele quem forma no aluno o gosto ou o desgosto pela escola, a motivação ou não pelos estudos; o entendimento da significância ou insignificância das áreas e objetos de estudo; a percepção de sua capacidade de aprender, de seu valor como pessoa[...]. (LUCK, 2002, p. 28).

Destaca-se, assim, a importância da equipe gestora nesse processo, pois é dele o papel de fazer com que o professor sinta-se estimulado por meio de uma valorização, não estamos aqui falando de valorização salarial, mas de uma valorização que poderá de certa forma resgatar a motivação desses profissionais. Afinal, quem não gosta de ser elogiado, receber atenção e ser ouvido, tudo isso faz com que se sintam importantes e, a partir daí, estimulados a fazer sempre mais, tendo a certeza de que seu trabalho está sendo reconhecido.

O coordenador pedagógico que tinha antes como principal função controlar, fiscalizar o trabalho dos professores, deve hoje ser visto como aliado do professor no sentido de contribuir na construção de um trabalho pedagógico de qualidade. Sendo assim, esse deve acompanhar o trabalho do professor o acolhendo em suas dificuldades, fazendo críticas quando necessário e comprometendose com a busca de melhores condições de trabalho na escola. Agindo dessa forma, o coordenador poderá fazer com que seus professores se sintam mais seguros, capazes, valorizados e motivados a realizar atividades diversificadas, interessantes, aulas prazerosas capazes de chamar a atenção dos alunos fazendo com que aprendam com mais facilidade. 
V. 13, n. 1: 2017.

Na visão da Escola Municipal de Ensino Fundamental Visconde de Mauá tanto os gestores como os professores comentam que a motivação é interna do ser humano, já na Escola Estadual de Ensino Fundamental Dolores Paulino a maioria comenta que a motivação é intrínseca.

Ambas as escolas comentam que basicamente a motivação é interna. Gomes (1975) observou em seus estudos que os indivíduos empenhavam-se mais em atividades de que gostavam, tais como os "hobbies" ou atividades de lazer, e designou esse tipo de motivação como intrínseca, isto é, algo que motiva comportamentos que, por sua vez, são fonte de motivação, através do aumento da satisfação pessoal e das sensações de competência e controle sobre as suas próprias ações.

\section{Considerações Conclusivas}

Neste trabalho buscamos compreender sobre o processo de motivação dos professores e da equipe gestora, por meio de leituras dos autores que dão sustentação teórica ao estudo e aos questionários respondidos por professores e pela equipe gestora das escolas entrevistadas.

Após a leitura fundamentada e do resultado da análise, pude perceber que melhorias estão ocorrendo no âmbito escolar, na forma de preparar aulas, de mediar o conhecimento e de aperfeiçoamento contínuo, mas me preocupei com a resistência por parte dos colegas em responder ao questionário, instrumento desta pesquisa.

Acredita-se que a causa possível dessa resistência à mudança seja, principalmente, a acomodação por parte dos professores que, por vezes, apresentam falta de comprometimento observada em alguns momentos na escola, preocupam-se e investem pouco em formação continuada, aceitam o desenvolvimento de todos os segmentos da sociedade e com ele o desenvolvimento da escola, sem questionar. Isso pode ser um problema, pois os estudantes do século XXI não são os mesmos do século XX. Hoje com o avanço das tecnologias ficou mais fácil à comunicação, com isso, as diferenças dos estudantes dessas épocas são gritantes. Além do mais, não podemos perder de vista que a educação é o caminho para que se crie uma sociedade justa e comprometida.

Para isso, precisamos estar mais bem preparados para lidar com o excesso de informações. Nesse contexto, Perrenoud (2000) enfoca a questão da competência do professor em relação à formação profissional, ele afirma que é imprescindível saber para ensinar bem em uma sociedade em que o conhecimento está cada vez mais acessível, e apresenta dez habilidades necessárias ao 
V. 13, n. 1: 2017.

professor. Salienta-se, entre elas, a de organizar e dirigir situações de aprendizagem, administrar a progressão das aprendizagens, trabalhar em equipe e utilizar novas tecnologias.

Desse modo, é evidente que a qualidade do ensino passa pela gestão democrática, que estabelece mecanismos da participação de todos os segmentos da comunidade escolar nas decisões administrativas, pedagógicas e financeiras da escola, ajuda na superação dos problemas encontrados na gestão, pois a efetiva interação dos que fazem a escola é capaz de promover uma educação dinâmica, participativa e de qualidade. A gestão democrática é indispensável para formação de uma cultura de interação entre todos, e ela é a responsável pela transformação da escola transformando-a em um local onde a informação, o conhecimento e a cidadania estão sempre presentes.

Diante disso, fica evidente a grande importância que a motivação tem no processo de ensino e aprendizagem e, principalmente, a motivação da equipe gestora que pode influenciar de forma positiva nesse processo. Para isso, é necessária uma parceria entre gestão e professores, com função orientadora e, acima de tudo, que busque meios de manter sempre uma equipe motivada, proporcionando assim um ambiente prazeroso e estimulador favorecendo um ensino de qualidade.

Como exposto anteriormente, a motivação pode ser observada sob dois ângulos, um que é interno, e o outro que é externo. Destaca-se nos questionários que ambas as escolas questionadas, tanto professores com gestores, acreditam que a motivação nasce com o ser humano, ou seja, ela é interna.

Em síntese, não é um trabalho a ser acabado, pois a cada dia surgem novos desafios em relação a nossa educação e, por isso, o tema da motivação estará sempre se renovando. Além de que, esta pesquisa abrangeu pequena parcela de nossas escolas e sabemos que poderá avançar em outra oportunidade.

\section{REFERÊNCIAS BIBLIOGRÁFICAS}

ADAIR, J. Liderança e Motivação. 2. ed. São Paulo: Clio, 2010.

BRASIL. Lei 9.394 de 20 de dezembro de 1996. Disponível em: <http://www.planalto.gov.br/ccivil_03/leis/19394.htm> Acesso em: 10 mar.2014.

BOCK, A. M. B. (org). Psicologias: uma introdução ao estudo de psicologia. 13. ed. São Paulo: Saraiva, 1999 
V. 13, n. 1: 2017.

BZNECK, J. A. A motivação do aluno: aspectos introdutórios. In: BORUCHOVITH, E. (org). A motivação do aluno. Contribuições da psicologia contemporânea. 4 ed. Petrópolis, RJ: Vozes,2009.p.9-36.

GOMES, J. F. A estrutura da inteligência e a criatividade. Rev. Portuguesa de Pedagogia. Coimbra: Casa do Castelo, 1975.

GUIMARÃES, S. E.R. Motivação intrínseca, extríncica e o uso de recompensas em sala de aula. In: BORUCHOVITCH, E. (Org). A motivação do aluno. Contribuições da psicologia contemporânea. 4. ed. Petrópolis: Vozes, 2009.p. 37-57.

LAKATOS, E. M.; MARCONI, M. de A. Fundamentos de metodologia científica. São Paulo: Atlas, 2003.

LUCK, H. Liderança em gestão escolar. 2. ed. Petrópolis, RJ: Vozes,2008. Vozes,2010b.

Concepções e processo democráticos de gestão educacional. 5. ed. Petrópolis: Ação Integrada: Administração, Supervisão e Orientação Educacional. 19 ed. Petrópolis: Vozes, 2002.

MINAYO, M. C. (org). Pesquisa Social. Teoria, método e criatividade. Petrópolis: Vozes, 2008.

PERRENOUD, P. 10 novas competências para ensinar. Porto A legre: ARTMED, 2000.

ROSAR, M.F.F. A dialética entre concepção e a prática da "gestão democrática" no âmbito da educação básica no Brasil. Educação \& Sociedade, Campinas, Dezembro, 1992.

SAVIANI, D. A nova lei da educação - LDB: trajetória e limites. Campinas: autores associados, 1997.

VIEIRA, S. L. Educação Básica: política e gestão escolar. Líber livro, fortaleza, 2008.

V.21, n.60

Gestão, avaliação e sucesso escolar: recortes da trajetória cearense. Estudos avançados. 